\title{
QUE VENHA 2017, E TRAGA BOAS NOTÍCIAS PARA O DIREITO FINANCEIRO
}

Coluna publicada em 10.1.2017: <https://www.conjur.com.br/2017-jan-10/ contas-vista-venha-2017-traga-boas-noticias-direito-financeiro $>$

Foi-se o ano de 2016, alardeado por todos como muito difícil, chegando melancolicamente ao fim.

Para o Direito Financeiro, também não foi dos melhores, apesar de não ter sido tão ruim quanto o de 2015 , que começou mal ${ }^{1}$ e terminou ainda pior. $^{2}$

Questôes financeiras ocuparam o centro das atenções, e o impeachment da Presidente da República por crimes de responsabilidade em matéria orçamentária, se de um lado evidenciou a má conduta na gestão das finanças públicas, ao menos mostrou a força da legislação financeira e a necessidade de que seja respeitada, bem como a independência dos órgãos responsáveis pelo controle externo, como os Tribunais de Contas e o Congresso Nacional. ${ }^{3}$

Vislumbra-se um ano de dificuldades, e esperamos que traga avanços no âmbito do Direito Financeiro que possam colaborar para a recuperação da economia. $\mathrm{Ou}$, ao menos que não se dê continuidade à degradação que foi imposta às normas de responsabilidade fiscal nos últimos anos.

Inicia-se com notícia da má situação financeira de Estados e Municípios, e a chance que está sendo dada aos Estados para que possam se reerguer, com a recen-

1 Coluna O Direito Financeiro precisa ser levado a sério, e 2015 começou mal, publicada em 10 de fevereiro de 2015 e que consta neste livro.

2 Coluna 2015: o ano de triste memória para o Direito Financeiro que não quer terminar, publicada em 15 de dezembro de 2015 e que consta neste livro.

3 Coluna Julgamento do TCU que reprovou contas do governo entrou para a história do Direito Financeiro, publicada em 20 de outubro de 2015 e que consta neste livro. 
te publicação da Lei Complementar 156, em 28.12.2016. ${ }^{4}$ Esta lei autoriza que a União reestruture as obrigações financeiras estaduais tanto por meio da prorrogação dos prazos de pagamento quanto pela via da redução das prestações. Assim, os contratos de refinanciamento firmados com a União (como aqueles ocorridos no bojo da Lei 9.496/1997) admitem prorrogação dos prazos de vencimento das parcelas, esperando-se que, com a reordenação do cronograma dos pagamentos se alivie a difícil situação financeira dos Estados. E, além da nova organização dos pagamentos, autoriza-se ainda a União a diminuir o montante das prestações - reduções extraordinárias que, em relação ao conturbado segundo semestre de 2016, podem chegar a $100 \%$ da parcela mensal devida (ver artigo $3^{\circ}$, $\$ 3^{\circ}$, da Lei Complementar 156). ${ }^{5}$

Além das condições de revisão dos pagamentos, vale a pena destacar ao menos outros dois aspectos do processo de aprovação da Lei Complementar 156.

O primeiro é que o Congresso Nacional decidiu retirar as contrapartidas dos Estados previstas no projeto. Isto é, as principais condiçōes e medidas de reforço à responsabilidade fiscal que estes entes deveriam cumprir para ter acesso aos benefícios de eventual reestruturação perante a União não estão previstas no texto final, mantendo-se apenas algumas exigências de divulgação de informações sobre a execução orçamentária e financeira. Entre estas contrapartidas estariam a redução de despesas de pessoal, suspensão de reajustes salariais e aumento das contribuições previdenciárias dos servidores.

Ausentes as contrapartidas na lei complementar, houve como contrarreação do governo o veto a medidas de alívio mais imediato das finanças estaduais aprovadas pelo Congresso, chamadas de "regime de recuperação fiscal". Entre as faculdades concedidas ao ente participante de tal regime se encontrava a suspensão temporária dos pagamentos previstos nos contratos com a União - uma moratória de até 36 meses.

Sem as necessárias medidas de ajuste estrutural para que recebam benefícios financeiros, como a suspensão de pagamentos da dívida pública, a federação introduziria em um cenário de recursos já escassos um novo elemento de instabilidade: o "risco moral" devido à percepção de que a responsabilidade fiscal é desnecessária, pois sempre haverá a perspectiva do socorro federal. Já tratamos deste assunto

4 Que "estabelece o Plano de Auxílio aos Estados e ao Distrito Federal e medidas de estímulo ao reequilíbrio fiscal”.

5 Desde que a redução não ultrapasse o valor mensal de 500 milhões de reais para cada parcela mensal, por Estado (como consta do art. $3^{\circ}, \$ 5^{\circ}$ ). 
quando analisamos as medidas de refinanciamento das dívidas subnacionais nos anos 1990 e os objetivos de estabilização pretendidos com a Lei de Responsabilidade Fiscal. ${ }^{6}$ Recentemente, Selene Peres Nunes voltou a analisar a questão, e sintetiza o problema: "a cada nova renegociação, gerava-se a expectativa de que o ajuste fiscal não era necessário porque sempre seria possível empurrar a dívida para o Governo Federal. Essa expectativa estimulava inadimplências sucessivas e frouxidão fiscal. Afinal, por que assumir o ônus político de ajustar as contas, se a União protegeria os inadimplentes?"

Uma medida que não é isenta de críticas, típica da sempre presente "administração-bombeiro", dada a "apagar incêndios". No entanto, ante o fato consumado, só resta torcer para que dela seja feito bom uso, e quem sabe os Estados consigam sair do inusitado "estado de calamidade", mais uma novidade que apareceu neste ano de 2016 no Direito Financeiro, já contaminando vários entes da federação. ${ }^{8}$

$\mathrm{E}$ é bom que os Estados possam recuperar suas finanças rapidamente, pois necessidades para ser atendidas não faltam. $\mathrm{O}$ ano já começa com uma delas, extremamente grave e muito dispendiosa - a situação carcerária -, esta indiscutivelmente em um verdadeiro "estado de calamidade". Manchete dos principais meios de comunicação do país, ${ }^{9}$ o tema foi objeto de atenção em todo o mundo durante a semana passada, em razão do lamentável episódio ocorrido em Manaus no primeiro dia do ano, em que uma rebelião interna levou à morte de dezenas de detentos, e poucos dias depois o fato se repete em Boa Vista, Roraima. O tema não é novo, já foi objeto de referência neste espaço (Coluna Solução para a crise carcerária tem significativo reflexo orçamentário $0^{10}$ ) e está "sub-judice" pela inovadora ADPF 347, que tem por objeto a declaração do "estado de coisas inconstitucional" do sistema penitenciário brasileiro. Destaque deve ser dado ao fato de já ter sido concedida a medida liminar que, entre outras providências, determinou a liberação e vedou o contingenciamento dos recursos do Fundo Penitenciário Nacional -

6 Coluna Refinanciar as dividas nada mais é do que postergar problemas, publicada em 3 de maio de 2016.

7 O risco moral do refinanciamento de dívidas. Blog da Selene, 17 de outubro de 2016. Disponível em: <http://www.selene.blog.br/single-post/2016/10/17/O-risco-moral-do-refinanciamento-de-d\%C3\%ADvidas>.

8 Coluna Crise leva as finanças públicas ao "estado de calamidade", publicada em 28 de junho de 2016.

9 Incluindo a capa das revistas semanais, como Veja (A explosão da barbárie nas prisões brasileiras, edição 2152), Época (O país da carnificina, edição 968), IstoÉ (Os chefes do crime que apavoram o Brasil, edição 2456) e Carta Capital (Massacre amazônico, edição 934).

10 Publicada em 25 de agosto de 2015 e que consta deste livro. 
Funpen. Recentemente, a Medida Provisória 755, de 19.12.2016, facilitou o repasse de recursos do fundo a Estados e Municípios, por meio das transferências voluntárias, ${ }^{11}$ e agora de forma "direta", com a diminuição de exigências para a transferência dos recursos.

Outras expectativas se formam, como a do julgamento definitivo das contas de governo pelo Congresso Nacional referente aos exercícios de 2014 e 2015, cujos respectivos pareceres prévios já foram elaborados pelo TCU, propondo, em ambos os casos, a rejeição das contas, em face das graves irregularidades encontradas (Acórdão TCU 2.461/2015, j. 7.10.2015, rel. Min. Augusto Nardes, referente às contas de 2014; e Acórdão TCU 2.523/2016, j. 5.10.2016, rel. Min. José Múcio Monteiro, referente às contas de 2015).

Estaremos também sob o "Novo Regime Fiscal”, tendo em vista a aprovação da Emenda Constitucional 95, publicada em 15.12.2016, decorrente da já famosa "PEC do Teto", com medidas polêmicas, voltadas a tentar estabelecer limitação constitucional para as despesas públicas primárias, cuja análise merece maior atenção, inviável de ser feita nesse curto espaço. Por ora o melhor é ser otimista, e tentar ver os aspectos positivos, destacados com muita propriedade recentemente nesta seção por Júlio Marcelo de Oliveira, para quem "A fixação de um limite constitucional para o crescimento das despesas primárias por um período razoável de pelo menos dez anos, podendo ser revisto a partir de então, passa uma mensagem extremamente positiva para os agentes econômicos, de confiança no comportamento e na responsabilidade do Estado na gestão de seus recursos e na sua capacidade de honrar e gerenciar sua dívida". ${ }^{12}$

Mas não há como deixar de registrar que o desapreço pelo planejamento parece afigurar-se como uma questão suprapartidária. Não se fala no PPA vigente para o período 2016-2019, e com o novo governo o que se espera é que seja cumprido, ou, caso não se tenha intenção de fazê-lo, em face da mudança de governo, que seja proposta modificação e aprovada o quanto antes. Afinal, é preciso documentar e deixar explícitas as prioridades para os próximos três anos.

E a LDO, como está se tornando praxe, voltou a ser publicada intempestivamente (Lei 13.408, publicada somente em 26 de dezembro, seis meses após o prazo

11 Sobre o assunto, veja-se DALLAVERDE, Alexsandra K. As transferências voluntárias no modelo constitucional brasileiro. Série Direito Financeiro (Coord. José Mauricio Conti). São Paulo: Blucher, 2016. A versão eletrônica do livro pode ser baixada gratuitamente no site da Editora Blucher.

12 Coluna $O$ que há de bom no novo regime fiscal?, publicada em 22 de novembro de 2016. 
constitucionalmente fixado). Tendo o novo governo assumido provisoriamente em 12 de maio do ano que passou, pode até ser compreensível alguma dificuldade em aprovar esse documento com decisões tão importantes ${ }^{13}$ até o final de junho, como deveria, mesmo porque assumiu definitivamente somente em agosto. Mas não é razoável publicar a lei de forma simultânea à Lei Orçamentária, tornando a LDO atualmente uma verdadeira peça de ficção, deixando de ter relevância como lei de planejamento para ficar com sua função anômala e secundária de regular questóes mais voltadas à execução orçamentária, servindo como substituto das lacunas da Lei 4.320. Aliás, esta é outra oportunidade que não se pode perder nesse ano que se inicia, pois os projetos que a substituem tramitam a passos lentos, e nada melhor do que promover a aprovação da Lei de Qualidade Fiscal.

Não são só os Estados, mas também e principalmente os Municípios, cujos Prefeitos tomaram posse neste primeiro dia do ano, que se encontram em severas dificuldades financeiras, como noticiado na mídia, que foi praticamente unânime em ressaltá-las. Sabendo que o primeiro ano de mandato não é próprio para cumprir promessas ${ }^{14}$, e não há milagres na gestão e nas contas públicas, ${ }^{15}$ espera-se que iniciem seus mandatos não esquecendo que devem desde já dar início à elaboração do plano plurianual, ${ }^{16}$ e agindo com responsabilidade, especialmente fiscal, pois lição dada pelo Direito Financeiro no ano de 2016 certamente não foi e não será esquecida.

Que todos enfrentem as dificuldades com criatividade, desde que não seja na contabilidade, pois o Direito Financeiro ainda não entrou na era da "pós-verdade"; nesse aspecto é conservador, e exige a verdade nas contas públicas!

13 Decisóes financeiras fundamentais são tomadas na LDO, publicada em 18 de outubro de 2016.

14 Coluna No primeiro ano de mandato, não se cumprem promessas, publicada em 20 de novembro de 2012, e que consta deste livro.

15 Coluna Ano e prefeitos "novos" não trazem milagrosamente melhor gestão, por Élida Graziane Pinto, publicada no Conjur em 4 de janeiro de 2017.

16 Coluna Planejamento municipal precisa ser levado a sério, publicada em 24 de setembro de 2013, e que consta deste livro. 
